\title{
A CARTILHA DESERTO VERDE NO RIO DE JANEIRO COMO RECURSO DIDÁTICO NO ENSINO DE GEOGRAFIA E LITERATURA
}

\section{THE “CARTILHA DESERTO VERDE NO RIO DE JANEIRO” AS RESOURCE TEACHING IN GEOGRAPHY AND LITERATURE}

\section{LA “CARTILHA DESIERTO VERDE EN RÍO DE JANEIRO" COMO RECURSO DIDÁCTICO EN LA ENSEÑANZA DE LA GEOGRAFÍA Y LA LITERATURA}

\author{
Débora Ventura Klayn Nascimento ${ }^{1}$ \\ Universidade Federal do Rio de Janeiro, Rio de Janeiro, Brasil \\ Thiago Lucas Alves da Silva ${ }^{2}$ \\ Secretaria Municipal de Educação, Rio de Janeiro, Brasil
}

\begin{abstract}
Resumo: Este trabalho é um esforço interdisciplinar de desenvolver, a partir da ligação entre Geografia e Literatura, uma cartilha baseada em uma narrativa com a temática da monocultura do eucalipto, denominada politicamente pelos movimentos sociais como Deserto Verde. A criação e o uso de uma cartilha como recurso pedagógico na educação básica têm como intuito valorizar o tema da monocultura do eucalipto, que tem sido palco de disputas e debates, além de facilitar o aprendizado de conceitos e conteúdos associados à Geografia e à Literatura. Essa opção metodológica busca possibilitar a abordagem do tema, por meio de uma linguagem mais próxima à realidade dos alunos, contribuindo para a apropriação e ressignificação da temática, por meio da linguagem literária.
\end{abstract}

Palavras-chave: Interdisciplinaridade; Deserto Verde; Narrativa.

\begin{abstract}
This work is an interdisciplinary effort to develop, based on the connection between Geography and Literature, a primer based on a narrative with the theme of eucalyptus monoculture, politically named by social movements as the Green Desert. The creation and use of a booklet as a pedagogical resource in basic education aims to enhance the theme of eucalyptus monoculture, which has been the scene of disputes and debates, as well as facilitating the learning of concepts and content associated with Geography and Literature. This methodological option seeks to enable proximity to the theme, through a language closer to the reality of students, contributing to the appropriation and (re)signification of the theme through literary language.
\end{abstract}

Keywords: Interdisciplinarity; Green Desert; Narrative text.

\footnotetext{
${ }^{1}$ Universidade Federal do Rio de Janeiro. Doutoranda pelo Programa Interdisciplinar de Linguística Aplicada - PIPGLA/UFRJ. E-mail: deboraklayn@gmail.com

2 Secretaria Municipal de Educação do Rio de Janeiro-RJ, Professor de Geografia, E-mail: thiagogeoffp@yahoo.com.br
} 
Resumen: Este trabajo es un esfuerzo interdisciplinario para desarrollar, basado en la conexión entre Geografía y Literatura, una cartilla basada en una narración con el tema del monocultivo de eucalipto, llamado políticamente por los movimientos sociales como el Desierto Verde. La creación y el uso de un folleto como recurso pedagógico en educación básica tiene como objetivo mejorar el tema del monocultivo de eucalipto, que ha sido escenario de disputas y debates, así como facilitar el aprendizaje de conceptos y contenidos asociados con Geografía y Literatura. Esta opción metodológica busca permitir la proximidad al tema, a través de un lenguaje más cercano a la realidad de los alumnos, contribuyendo a la apropiación y (re)significación del tema a través del lenguaje literario.

Palabras clave: Interdisciplinariedad; Desierto Verde; Narración.

\section{INTRODUÇÃO}

A ciência é grosseira, a vida é sutil, e é para corrigir essa distância que a literatura nos importa. (BARTHES, 1977, p. 25).

O trabalho ora apresentado é fruto de um esforço interdisciplinar para desenvolver a temática do espaço agrário fluminense, a partir de articulações entre o ensino de Geografia e de Literatura. O objetivo é a elaboração de uma cartilha na qual informações provenientes de uma pesquisa científica da área da Geografia sejam transpostas para um texto narrativo, de modo a facilitar a socialização das descobertas científicas, transportando-as para o mundo da vida prática, vida esta nem sempre tão sutil como nas palavras do escritor, filósofo e crítico literário Roland Barthes. Por ser um projeto ainda em fase inicial, o intuito nesse momento é partilhar a experiência do processo de construção desse material de caráter interdisciplinar e de sua intenção de uso com estudantes da educação básica e militantes de movimentos sociais.

O assunto escolhido para o desenvolvimento do material diz respeito à introdução da monocultura do eucalipto no estado do Rio de Janeiro, denominada politicamente pelos movimentos sociais como 'Deserto Verde'. A criação e uso de uma cartilha com texto narrativo como recurso pedagógico tem como intuito valorizar o tema e discutir conteúdos geográficos, a partir da tipologia textual narrativa e da linguagem literária. Essa opção 
metodológica busca aproximar o tema em questão de uma linguagem mais próxima à realidade dos alunos da educação básica, para os quais o texto narrativo se mostra um recurso didático facilitador da construção de conhecimentos. Desse modo, espera-se articular conceitos pertinentes ao ensino de Geografia, por meio do uso de um material que, apesar de didático, alicerça-se em uma linguagem literária.

A esse respeito, faz-se necessário destacar que o gênero textual cartilha, por si só, não figura entre os gêneros enquadrados dentro da esfera literária, uma vez que, diferente dos textos literários, as cartilhas possuem uma finalidade intencional didática, ou seja, nascem com o declarado propósito de ensinar algo. Os textos literários, por sua vez, possuem como uma de suas características marcantes a não intencionalidade de usos práticos ou didáticos na sociedade, embora saibamos que eles possam vir a desembocar nesses papéis. O diálogo entre geografia e literatura a que alude o presente trabalho diz respeito, portanto, à tentativa de transposição da linguagem argumentativa e científica da pesquisa geográfica em questão para uma linguagem narrativa, mais próxima ao ato de contar uma história, permeado pela busca do fazer estético com a linguagem. A literatura estará, assim, abrigada dentro do recurso didático da cartilha.

Desse modo, a construção da cartilha como recurso didático/pedagógico se configura como um importante elemento a ser usado nas aulas de Geografia, além de constituir possibilidade de integração com as aulas de Literatura, uma vez que pode possibilitar o despertar - mediante a adoção de uma linguagem narrativa e lúdica - da reflexão crítica sobre problemáticas que afetam o cotidiano dos alunos. Nesse sentido, o uso da literatura pode constituir a possibilidade de ressignificar os aprendizados construídos nas aulas de geografia. Isso porque, como um dos elementos do letramento literário - "o processo de apropriação da literatura enquanto construção literária de sentidos" (PAULINO; COSSON, 2009, p. 67) -, a leitura literária envolve apropriação, isto é, o ato de se apropriar do texto, tomando-o para si e o ressignificando a partir das próprias vivências e experiências, que se dão em contextos e espaços sociais nos quais a pessoa se insere e com os quais interage.

Logo, a temática do espaço agrário fluminense, a partir do chamado deserto verde (monocultura de eucalipto), demanda o entendimento crítico de fenômenos sociais como a produção do espaços e suas diferentes formas apropriação, as relações entre campo-cidade, 
o reconhecimento dos movimentos sociais e demais sujeitos do campo, a forma desigual de atuação do Estado, a subordinação da produção rural aos interesses industriais e os efeitos da globalização na escala da vida local.

A construção da cartilha interdisciplinar representa a junção de trabalhos anteriormente desenvolvidos de forma individualizada de dois pesquisadores de áreas distintas, que trilharam caminhos diversos em sua formação: um enveredando, ainda na graduação em Geografia, pelos trabalhos na Geografia Agrária e, posteriormente, na pósgraduação, em curso de caráter interdisciplinar envolvendo Economia, Sociologia, Antropologia, aprofundando-se em estudos e pesquisas sobre questão agrária, assentamentos rurais e políticas públicas para a agricultura; outro, aprofundando-se, desde a graduação em Letras, em estudos da área da educação e, posteriormente, na pós-graduação, participando de pesquisas sob o enfoque da Linguística Aplicada, tendo, sobretudo a partir do curso de Doutorado, se dedicado à pesquisa sobre produção de material didático e o ensino de Literatura.

Apesar dos caminhos trilhados no âmbito acadêmico terem sidos distintos, ambos os pesquisadores têm atuado de forma conjunta no mesmo espaço escolar e, por muitas vezes, acabam por lecionar nas mesmas turmas. Tais relações espaço-temporais fizeram com que os pesquisadores enfrentassem as mesmas mazelas sociais que impactam diretamente na vida dos alunos da Escola Municipal Vereador Américo dos Santos, localizada no município de Mesquita (Baixada Fluminense), local de trabalho e palco do projeto piloto.

Por entenderem que questões do processo de ensino-aprendizagem dos seus alunos ultrapassavam as barreiras disciplinares, ambos os professores, coerentes com suas formações políticas e pedagógicas, buscaram formas alternativas e parcerias no enfrentamento das situações-problemas presentes no espaço escolar. Além das dificuldades enfrentadas nesse espaço, ambos os pesquisadores têm se deparado, em suas áreas de conhecimento, com a distância entre o saber produzido na academia e o saber escolar (sobretudo na produção de materiais didáticos). O primeiro é aquele responsável pela construção do conhecimento sobre a realidade mediante a operacionalização de categorias filosóficas, que muitas vezes estão distantes das experiências e vivências dos alunos. Já o segundo, o saber escolar, "se distância da academia ao ter sua construção mais associada ao 
cotidiano e à experiência do professor" (CAVALCANTI, 1998, p. 104), que nesse sentido assume o protagonismo da produção do saber, diferente da sua respectiva área acadêmica, onde o cientista é o principal agente. Porém, ambos os pesquisadores compreendem que esses tipos de saberes devem estar em constante processo de aproximação, por meio das mediações que transformam os conhecimentos repletos de rigores teóricos e conceituais em conteúdos escolares mais próximos da realidade dos alunos, buscando facilitar o processo de ensinoaprendizagem.

Nesse sentido, os pesquisadores entendem que é necessário buscar a interdisciplinaridade, como um dos mecanismos que podem ajudar a fomentar o estímulo dos alunos pelo conhecimento, rompendo a disciplinarização tão peculiar nas escolas e a hierarquização das aulas. Partindo desse pressuposto, encontramos um horizonte teóricometodológico interessante para a elaboração do material, já que a proposição surge através da construção de conhecimentos amparados no saber acadêmico, que com a mediação pedagógica e o saber escolar, buscamos tornar os conteúdos geográficos e literários mais acessíveis, ou seja, trabalhar conhecimentos repletos de rigores teóricos e conceituais, em conteúdos escolares acessíveis para o processo de ensino-aprendizagem na educação básica, que possibilite a formação de estudantes que sejam leitores críticos de textos e das realidades nas quais se inserem.

Se a realidade no mundo globalizado é cada vez mais complexa e contraditória, emerge, de forma cada vez mais intensa, a necessidade de análises mais integradoras e holísticas para compreendermos as transformações em curso na sociedade. É nesse cenário socioespacial que se acredita ser muito rica a possibilidade de interpretação/compreensão da realidade, oriunda da imbricação do conhecimento geográfico e da literatura. $\mathrm{O}$ ensino interdisciplinar, realizado a partir da Geografia e da Literatura, pode promover a ampliação das concepções conceituais para os estudantes, ao mesmo tempo em que tem potencial para estimular o acesso e o uso de novas linguagens e, portanto, promover o desenvolvimento da capacidade crítica nos alunos para além do dogmatismo e da hierarquização de valores e conhecimentos orientados pelas metodologias positivistas ou mesmo pela exacerbação do relativismo estimulado pelos autores pós-modernos.

A literatura, aqui entendida em sua acepção mais ampla, como aponta Antonio 
Candido, isto é, como todas as "criações de toque poético, ficcional ou dramático em todos os níveis de uma sociedade, em todos os tipos de cultura...” (CANDIDO, [1970], 2011, p. 180) - em consórcio com a ciência geográfica, pode permitir a superação da estruturação dos espaços sociais pela maleabilidade da imaginação. Ademais, literatura constitui um direito essencial, uma vez que não há pessoa capaz de viver sem alguma espécie de fabulação. Porém não se trata aqui de sublimação da imaginação e nulidade dos postulados científicos, mas sim de promoção da ampliação interpretativa do que seja o mundo e como ele é organizado.

Nesse sentido, a construção de uma cartilha pautada no entrelaçamento das áreas de geografia e literatura busca um processo de ensino-aprendizagem que permita a edificação de uma interdisciplinaridade e que contribua para que os alunos tenham ampla compreensão das relações sociais, culturais, históricas e geográficas, "ampliando suas possiblidades de compreensão e intervenção nos seus espaços do cotidiano” (MOREIRA, 1987, p. 46), ou seja, nos seus lugares.

O ensino interdisciplinar, a partir da relação entre as áreas citadas, busca promover a superação de uma educação estática e vislumbrar possibilidades educacionais mais fluidas e que possam transitar em diferentes esferas de atuação humana. Segundo Castellar (2010, p. 77), um dos desafios colocados para os professores nos dias de hoje está em "superar os vícios de uma educação estática, inerte e ineficaz", investindo em uma educação com mais qualidade e criatividade. $O$ desafio da superação da paralisia pedagógica passa obrigatoriamente pela ampliação das linguagens apresentadas e trabalhadas em sala de aula; logo, a linguagem literária contribui dinamicamente para a aproximação efetiva dos alunos com a totalidade espacial, a partir de ideias mais criativas e muito mais próximas do cotidiano deles.

\section{OBJETIVOS}

O presente projeto tem por objetivo geral demonstrar a possibilidade de entrelaçamento entre as áreas de Geografia e Literatura na elaboração de materiais e abordagens pedagógicas voltadas tanto para a educação formal básica, quanto para movimentos sociais. Como objetivos específicos, almeja-se: (1) produzir material didático 
(cartilha) com a narrativa da introdução/desenvolvimento da monocultura do eucalipto (deserto verde) e seus impactos socioambientais no estado do Rio de Janeiro; (2) utilizar a cartilha para estimular o processo de ensino e aprendizagem nas aulas de Geografia e Português/Literaturas na educação básica; (3) utilizar a cartilha como fonte de pesquisa em cursos de formação de militantes de movimentos sociais, ligados à questão agrária no Rio de Janeiro.

Dada a grande dimensão regional das áreas impactadas com a introdução do cultivo de eucalipto em larga escala no estado do Rio de Janeiro, além do fato de o presente projeto ser independente e se encontrar em busca de parcerias e financiamento, coloca-se a possibilidade do desenvolvimento do projeto a longo prazo, mas, de imediato, propõe-se a execução de um projeto piloto, a ser realizado com estudantes do segundo segmento do ensino fundamental, na Escola Municipal Vereador Américo dos Santos, em Mesquita-RJ e nos cursos de formação da Rede Alerta Contra o Deserto Verde (RADV).

\section{METODOLOGIA}

Para a construção da cartilha, o primeiro passo foi a realização de uma pesquisa bibliográfica sobre o tema, entrevistas com produtores rurais, representantes dos movimentos sociais e funcionários públicos ligados aos órgãos envolvidos na questão agrária fluminense. Paralelamente, na intenção de transposição dos resultados da pesquisa para a tipologia narrativa e para a esfera literária, realizamos uma investigação sobre as características do texto narrativo, as especificidades do texto literário, e a elaboração de materiais didáticos. A próxima etapa diz respeito ao entrelaçamento dos resultados obtidos até o momento, com fins de construção de um material capaz de contribuir para um ensino de geografia em diálogo com as possibilidades oferecidas pela literatura.

\section{DO IMAGINÁRIO AO CONCRETO: DESENVOLVIMENTO E REFERENCIAL TEÓRICO DA PESQUISA}

Para a criação da cartilha Deserto Verde no Rio de Janeiro foi realizada uma pesquisa 
sobre o processo de introdução do cultivo de eucalipto para fins comerciais no estado do Rio de Janeiro. Atrelado a essa ação, foi necessário analisar como essa atividade estava inserida dentro de um contexto mais amplo de transformações do estado do Rio de Janeiro, que foi palco principal de grandes projetos de desenvolvimento nas últimas décadas. Essa pesquisa, bem como sua análise, constitui a primeira base teórica para o desenvolvimento da cartilha.

De posse da base teórica e de pesquisas empíricas, é fundamental buscar nas normativas educacionais o embasamento necessário para a produção da cartilha. De acordo com os Parâmetros Curriculares Nacionais (BRASIL, 1998), é necessário maior integração entre as disciplinas, inclusive nas propostas de temas transversais que proporcionam um trabalho que provoca interesse e curiosidade sobre a leitura do mundo e, é nessa linha que a cartilha está sendo desenvolvida. Assim, é possível estabelecer um elo entre os elementos que perpassam o texto da cartilha: as noções sobre a construção de um texto narrativo e as características de um texto literário; o referencial teórico e os resultados da pesquisa sobre a monocultura de eucalipto; além da análise do currículo local e das escolhas do conteúdo a ser apreendido pelos alunos.

Com relação à escolha do texto narrativo, o trabalho se embasa no fato de as narrativas serem um modo específico de construção e constituição da realidade, modo que faz parte da tradição cultural. Assim sendo, elas se mostram presentes nas vidas cotidianas desde as mais tenras idades: ainda no berço, o entendimento do mundo já é mediado a partir das narrativas que os cuidadores vão apresentando. Dessa forma, acostuma-se a ter a narrativa como mediadora de experiências e configuradora da construção social da realidade. Logo, importa que a escola atente à essa forma humana de conceptualizar o mundo, pois

a narrativa funciona como um 'guião' para ajudar-nos a fazer sentido. Utilizamo-na constantemente porque o social se apresenta a nós como uma narrativa e podemos aplicá-la seletivamente a quase todos os aspectos de nossas vidas (RABELO, 2011, p. 175).

No tocante às especificidades do texto literário, o trabalho busca a construção do ficcional a partir do real, na tentativa de possibilitar aproximação, identificação e ressignificação dos fatos narrados, uma vez que a literatura fornece a possibilidade de viver 
dialeticamente os problemas. Atenta ao fato de a literatura poder ser um instrumento consciente de desmascaramento de mazelas sociais (cf. CANDIDO, [1970], 2011), a proposta intenciona fazer uso dessa ferramenta para possibilitar o contato com espaços geográficos e sociais outros. Desse modo, entende-se que a partir do deslocamento possibilitado pela leitura literária, o aluno pode construir compreensões de realidades geográficas e sociais que não lhe estariam acessíveis ou perceptíveis sem a mediação textual.

Além disso, para a elaboração do texto base, é necessário compreender que o espaço agrário do estado do Rio de Janeiro é historicamente marcado pela notória força do latifúndio na sua apropriação e produção social, ditando as formas de ordenamento do território e de produção agrícola. Nas últimas décadas, o espaço agrário fluminense está diante de outro forte desafio para o seu desenvolvimento: o intenso processo de metropolização e urbanização. Tal espaço, tem hoje uma agricultura contrastante (RIBEIRO, 2002), na qual se encontra o latifúndio de características tradicionais (uma agricultura com certo grau de mecanização e/ou voltada para a produção gêneros agrícolas que possuem nichos de mercado), acampamentos e assentamentos rurais, onde se desenvolve uma agricultura familiar (ALENTEJANO, 2005) com produção voltada para a subsistência e venda de excedentes, entre outras formas.

Neste sentido, o espaço agrário fluminense tem sido marcado por um processo de desenvolvimento desigual (e combinado), que possibilitou esse quadro diverso e contraditório de atividades econômicas e formas de ocupação do espaço. Esse espaço contraditório é palco também de diversas práticas culturais que mantêm vínculos simbólicos com o rural e com as tradições das regiões do estado do Rio de Janeiro.

De modo geral, as regiões do estado do Rio de Janeiro vêm em maior ou menor grau sofrendo, desde os anos 1960, com uma séria crise de geração de emprego, pela ausência de reconversão produtiva das grandes propriedades, pela baixa rentabilidade da pecuária, pela “desertificação das suas terras, exauridas pelas formas de produção do café, da cana e pelo manejo da pecuária extensiva" (CRUZ, 2007, p. 3). Esse quadro contribuiu para que extensas áreas do interior do Rio de Janeiro apresentem um nível de aproveitamento agrícola muito inferior ao potencial produtivo das terras, o que reflete na predominância da pecuária bovina caracterizada por índices muito baixos de produtividade e pelo tradicional latifúndio. 
O processo histórico de implantação de monoculturas como a cana-de-açúcar e o café, combinadas com a pecuária extensiva, provocou uma imensa devastação da cobertura florestal, notadamente dos remanescentes da Mata Atlântica. Se utilizarmos a região do Noroeste como exemplo, a Mata Atlântica, de acordo com Instituto Estadual do Ambiente, está presente em apenas 4,6\% da área da região, que representa o maior percentual de desmatamento entre os domínios geoambientais (GUERRA; MARÇAL, 2010) do Estado³. Desse modo, o processo de espoliação da natureza (HARVEY, 2005) no Noroeste Fluminense possui similaridades com outros espaços, tais como a região do Médio Paraíba Fluminense e Norte Fluminense.

Com isso, a escolha do tema para a produção da cartilha Deserto Verde no Rio de Janeiro é fruto de inquietudes surgidas ao longo dos últimos anos, especialmente devido ao debate e à mobilização em torno da mudança da legislação estadual, que alterava as restrições ao plantio de eucalipto (monocultura) em larga escala no estado do Rio de Janeiro (Lei n. 5063/2007), à publicação de estudos que buscam forjar as bases teóricas e técnicas da "vocação regional" do espaço agrário fluminense para estabelecer o cultivo de monocultivos.

Cabe destacar aqui a mobilização de diferentes agentes da sociedade, como órgãos do Estado e da inciativa privada (empresas de celulose) na produção de materiais didáticos e técnicos em diferentes linguagens (cartilhas, vídeos, relatórios, pesquisa de opinião e outros) para fomentar a importância da produção de eucalipto em diferences espaços e para diferentes públicos. Tal medida não é isolada, pois se trata de uma ação que tem sido empreendida pelo agronegócio em diferentes regiões do Brasil, com destaque as para as campanhas publicitárias do ‘AGRO’ no horário nobre das grandes emissoras de televisão, a produção de material pedagógico distribuído nas escolas públicas e em cursos de formação continuada de docentes no interior de São Paulo.

Essas ações ratificam a necessidade político-pedagógico da produção de materiais didáticos e a utilização de diferentes linguagens, como se propõe a cartilha Deserto Verde no Rio de Janeiro, por nós idealizada, para se contrapor à homogeneização dos discursos e

\footnotetext{
${ }^{3}$ Informações do Tribunal de Contas do Estado do Rio de Janeiro (TCE/RJ). Estudos socioeconômicos dos municípios do estado do Rio de Janeiro.

Disponível em: http://www.tce.rj.gov.br/web/guest/estudos-socioecono-micos1. Acesso em: 27 ago. 2020.
} 
narrativas empreendidas pelas grandes corporações transnacionais do setor celulósicopapeleiro.

É dentro dessas disputas territoriais e de narrativas que a silvicultura comercial, notadamente o cultivo de eucalipto, faz parte de um projeto de desenvolvimento desigual e combinado (SMITH, 1988) que vem sendo desenvolvido no estado do Rio de Janeiro, pelo poder público em consonância com interesses do setor empresarial. Para esses agentes sociais, as plantações homogêneas (monocultura) de eucalipto em escala industrial são a base para estabelecer o agronegócio da madeira, desencadeando outras atividades ligadas ao capital industrial de base florestal.

Do ponto de vista geográfico, essa tentativa de ajuste espacial (HARVEY, 2013) ganha significado, haja vista a localização estratégica do território fluminense, que faz divisa com os estados do Espírito Santo, Minas Gerais e São Paulo. Esses estados possuem extensas áreas de cultivo de eucalipto e grandes empresas demandantes de madeira, como empresas siderúrgicas e ligadas ao setor de celulose e papel. Porém, esses estados possuem pouca possibilidade de expansão de suas áreas, devido às fortes mobilizações sociais de resistência e denúncia causadas pelos danos socioambientais ligados ao monocultivo do eucalipto e às empresas demandantes que vêm acarretando proibições do cultivo de eucalipto em novas áreas ou endurecendo as legislações.

Com isso, a aliança entre o Estado e setores empresariais tem em vista construir as bases para o deslocamento espacial do cultivo de eucalipto em escala industrial e, assim, possibilitar que as empresas de base florestal possam transformar o Rio de Janeiro em novo espaço de apropriação e acumulação (HARVEY, 2004) desse setor do agronegócio.

Desse modo, a cartilha Deserto Verde no Rio de Janeiro tem como objetivo apresentar e discutir os impactos do desenvolvimento do cultivo eucalipto no Rio de Janeiro, a partir dos principais fatos decorridos durante o processo de implantação dessa atividade econômica no território fluminense. Nesse sentido, a literatura pode oferecer caminhos significativos para ampliar a compreensão e o debate junto aos estudantes da educação básica, assim como militantes de movimentos sociais e sindicais. 


\section{CONSIDERAÇÕES FINAIS}

Na combinação de Geografia com Literatura, busca-se caminhos possíveis para que os alunos construam entendimentos sobre o ambiente em que vivem e, a partir daí, tomem decisões para possíveis mudanças. Parte-se do entendimento, portanto, de que é necessário criar expectativas, incentivando a leitura, fazendo com que o aluno crie o hábito de ler os textos e os contextos à sua volta, despertando para a curiosidade e o aprendizado. Nesse sentido, o trabalho com a cartilha nasce da premissa de que a leitura, seja ela de mundo (cf. FREIRE, 1988) ou de textos, deve ser um dos principais momentos em sala de aula, pois a formação de leitores, no sentido amplo do termo, é um dos papéis da escola e não somente das aulas de língua e literatura.

A criação da cartilha e sua utilização com alunos e militantes sociais permite discutir questões e conteúdos vistos como naturalizados no conjunto da sociedade, permitindo uma outra forma de observar os fenômenos sociais, ampliando a possibilidade de um novo olhar espacial e uma nova forma de ler o mundo.

Nesse sentido, o campo (o rural) geralmente é visto em consagradas obras literárias, livros didáticos ou mesmo em programas curriculares, como um local de atraso, selvagem, lento e homogêneo. Em contraposição, a cidade costuma ser apresentada como o espaço do moderno, da tecnologia, do dinâmico e do heterogêneo. Contudo, quando aproximamos o olhar para as relações sociais ali desenvolvidas, percebemos como esse mito contradiz o real. Por isso, o objetivo do uso da cartilha Deserto Verde no Rio de Janeiro será o de - por meio de um trabalho interdisciplinar, do uso de uma linguagem mais acessível e lúdica, sem perder a riqueza teórica e explicativa dos conceitos - permitir a compreensão das transformações socioespaciais em curso no espaço agrário fluminense e a desestabilização de ideias cristalizadas a respeito dessas transformações.

Por ser tratar de um trabalho em fase inicial, espera-se que os diálogos com os diferentes leitores da cartilha Deserto Verde no Rio de Janeiro possam se desdobrar em outros recursos didáticos interdisciplinares e na criação de novos materiais de ensino que visem a favorecer o processo de ensino-aprendizagem na formação de cidadãos críticos. 


\section{REFERÊNCIAS}

ALENTEJANO, Paulo Roberto Raposo. A evolução do espaço agrário fluminense. In: Geographia. Niterói, v. 13, p. 49-70, 2005.

BARTHES, Roland. Aula: aula inaugural da cadeira de semiologia literária do Colégio de França, pronunciada dia 07 de janeiro de 1977. São Paulo: Cultrix, 2007.

BRASIL. Secretaria de Educação Fundamental. Parâmetros curriculares nacionais: Geografia. Brasília: MEC/SEF, 1998. 435 p.

CANDIDO, Antonio. O direito à literatura. In: CANDIDO, A. Vários escritos. 4. ed. São Paulo: Duas cidades; Rio de Janeiro: Ouro sobre Azul, [1970] 2011. p. 171-193.

CASTELLAR, Sonia Maria Vanzella. Ensino de geografia. São Paulo: Cengage Learning, 2011 - (Coleção ideias em ação / coordenadora Anna Maria Pessoa de Carvalho).161 p.

CAVALCANTI, Lana de Souza. Geografia, escola e construção de conhecimento. Campinas: Papirus, 1998. 198 p.

FREIRE, Paulo. A Importância do Ato de Ler: em três artigos que se completam. 42.ed. São Paulo: Cortez - Questões da nossa época, 13 - [1988] 2001. 49 p.

GUERRA, Antonio José Teixeira; MARÇAL, Mônica dos Santos. (Org.). Geomorfologia ambiental. $3^{\mathrm{a}}$. ed. Rio de Janeiro: Bertrand Brasil, 2010. $189 \mathrm{p}$

HARVEY, David. Espaços de Esperança. (Título original: Spaces of Hope) Tradução: Adail Ubirajara Sobral e Maria Stela Gonçalves, São Paulo: edições Loyola, 2004. 1 ed.

. O novo imperialismo. São Paulo: edições Loyola, 2005.

. Os limites do capital. São Paulo: Boitempo, 2013. 1 ed.

MOREIRA, Ruy. O Discurso do avesso (para a crítica da Geografia que se ensina). $1^{\mathrm{a}}$ ed. Editora Dois Pontos: Rio de Janeiro, 1987.

RABELO, Amanda Oliveira. A importância da investigação narrativa na educação. Educação \& Sociedade, vol. 32, núm. 114, enero-marzo, 2011, p. 171-188.

PAULINO, Maria das Graças; COSSON, Rildo. Letramento literário: para viver a literatura dentro e fora da escola. In: ZILBERMAN, Regina; ROSLING, Tânia. (Orgs.). Escola e leitura: velhas crises, novas alternativas. São Paulo: Global, 2009, p. 61-79.

SMITH, Neil. Desenvolvimento desigual: natureza, capital e a produção de espaço. 1 ed. Rio 
Débora Ventura Klayn Nascimento Thiago Lucas Alves da Silva

de Janeiro: Bertrand Brasil, 1988.
Geografia, Literatura e Arte, v.2, n. 1, p. 22-35, jan./jun.2020

DOI: 10.11606/issn.2594-9632.geoliterart.2020.167454

Recebido em 07/03/2020.

Aceito em 04/09/2020.

Publicado em 15/10/2020. 